\title{
Modafinil in the treatment of excessive sleepiness
}

\section{Jonathan RL Schwartz}

INTEGRIS Sleep Disorders Center and University of Oklahoma Health Sciences Center, Oklahoma City, OK, USA
Correspondence: Jonathan RL Schwartz INTEGRIS Sleep Disorders Center of Oklahoma, 4200 S. Douglas Avenue, Suite 313, Oklahoma City, OK 73109, USA Tel +l 405636 IIII

Email schwjr@integris-health.com
Abstract: The wake-promoting agent modafinil is approved for the treatment of excessive sleepiness associated with obstructive sleep apnea (OSA), shift work disorder (SWD), and narcolepsy. In OSA, modafinil is recommended for use as an adjunct to standard therapies that treat the underlying airway obstruction. This article reviews the literature on modafinil (pharmacology, pharmacokinetics, efficacy, tolerability, and abuse potential), with emphasis on use of modafinil in the treatment of excessive sleepiness in patients with OSA, SWD, and narcolepsy. In large-scale, double-blind, placebo-controlled studies, modafinil improved objectively determined sleep latency, improved overall clinical condition related to severity of sleepiness, and reduced patient-reported sleepiness. Improvements in wakefulness were accompanied by improvements in behavioral alertness, functional status, and health-related quality of life. In patients with SWD, diary data showed modafinil reduced the maximum level of sleepiness during night shift work, level of sleepiness during the commute home, and incidence of accidents or near-accidents during the commute home when compared with placebo. Modafinil was well tolerated, without adversely affecting cardiovascular parameters or scheduled sleep. These findings and those of extension studies which reported improvements were maintained suggest modafinil has a beneficial effect on daily life and well-being in patients with excessive sleepiness associated with OSA, SWD, or narcolepsy.

Keywords: modafinil, excessive sleepiness, wakefulness, obstructive sleep apnea, shift work disorder, narcolepsy

\section{Introduction}

Modafinil, an orally administered wake-promoting agent, is indicated to improve wakefulness in adults with excessive sleepiness associated with obstructive sleep apnea (OSA), shift work disorder (SWD), and narcolepsy (PROVIGIL ${ }^{\circledR}$ 2007). In patients with OSA, modafinil is recommended for use as an adjunct to standard therapies prescribed for the underlying airway obstruction (PROVIGIL ${ }^{\circledR}$ 2007). Modafinil was first approved in the United States in December 1998 for use in narcolepsy and subsequently in January 2004 for use in OSA and SWD. This article reviews the literature on modafinil (pharmacology, pharmacokinetics, efficacy, tolerability, and abuse potential), with emphasis on use of modafinil in the treatment of excessive sleepiness in patients with OSA, SWD, and narcolepsy.

\section{Excessive sleepiness}

Excessive sleepiness is the inability to remain awake during situations when wakefulness and alertness are required or expected (Arand et al 2005; Wise 2006). It is a main presenting symptom of individuals seen in sleep clinics and affects a substantial proportion of the general population. In a survey conducted by the National Sleep Foundation, $37 \%$ of adults reported sleepiness severe enough to interfere with activities of daily living a few days or more each month; $16 \%$ of respondents indicated excessive sleepiness interfered with activities even more frequently (ie, a few days or more each week) (National Sleep Foundation 2002). Objective and subjective assessments 
of sleepiness in community-based samples suggest a prevalence of 24\%-36\% (Baldwin et al 2004; Mignot et al 2006; Singh et al 2006). Causes of excessive sleepiness include inadequate restorative sleep due to shortened duration or fragmentation, circadian rhythm disturbance or misalignment, dysregulation of intrinsic mechanisms responsible for promoting sleep and wakefulness, and the use of sedating medications (Roth and Roehrs 1996). Excessive sleepiness is a prominent symptom of various disorders of sleep and wakefulness (American Academy of Sleep Medicine 2001) and of other medical and psychiatric disorders.

In addition to impairing physical, cognitive, and psychosocial functioning, excessive sleepiness compromises the safety of individuals and the public at large. Sleepiness has been implicated in serious incidents in the workplace (Mitler et al 1988; Dinges 1995), and chronic sleepiness appears to be a significant independent risk factor for involvement in vehicular accidents (Gander et al 2004). A recent crosssectional survey found road accidents due to sleepiness are not limited to commercial drivers during the night or early morning hours; near-miss accidents due to sleepiness are common among other types of drivers and appear to predict who is at risk for any type of actual accident (Powell et al 2007). Individuals with disorders of sleep and wakefulness who have sleepiness as a prominent characteristic are among those who are at increased risk for sleep-related accidents (Lyznicki et al 1998; MacLean et al 2003; Drake et al 2004; Powell et al 2007).

\section{Disorders of sleep and wakefulness: obstructive sleep apnea, shift work disorder, and narcolepsy}

These three sleep disorders, though differing in origin, are all distinguished by excessive sleepiness. OSA affects an estimated $2 \%-4 \%$ of middle-aged adults (Young et al 1993). This chronic disorder is characterized by repeated episodes of partial or complete collapse of the upper airway during sleep. The partial or complete obstruction causes recurrent breathing difficulties, which are associated with arousals that disrupt sleep and may also cause hypoxemia. Elevated homeostatic sleep pressure and possibly hypoxic brain injury (Gale and Hopkins 2004; Veasey et al 2004; Morrell and Twigg 2006; Polotsky et al 2006; Zhu et al 2007) contribute to excessive sleepiness and other neurobehavioral and neuropsychological impairments in these patient. Nasal continuous positive airway pressure (CPAP) is an effective intervention for OSA (Engleman et al 1994a) that works to restore patency by pneumatically splinting the airway. However, clinically significant excessive sleepiness may persist for some patients who regularly use CPAP therapy (Sforza and Krieger 1992). In patients with severe OSA and daytime sleepiness who were optimally treated with CPAP therapy (6 or more hours nightly), 8 of 36 patients (22\%) subjectively reported ongoing daytime sleepiness (assessed by the Epworth Sleepiness Scale), and 12 of 23 patients (52\%) had ongoing objectively determined sleepiness (assessed by the MSLT) despite optimal CPAP therapy (Weaver et al 2007).

SWD is a circadian rhythm sleep disorder estimated to affect $32 \%$ and $26 \%$ of night shift and rotating shift workers, respectively (Drake et al 2004). The disorder is caused by an inability to adapt internally driven processes that regulate sleep and wakefulness (ie, circadian cycles and homeostatic sleep drive) to externally imposed sleep-wake schedules. Minimal criteria for a diagnosis of SWD are a primary complaint of excessive sleepiness or insomnia and temporal association of symptoms with work that occurs during the period of habitual sleep (American Academy of Sleep Medicine 2001). Individuals with SWD have a significantly greater risk for morbidity (ie, ulcers and depression) than shift workers without SWD or day workers who have identical symptoms (Drake et al 2004).

Narcolepsy is a chronic disorder of sleep/wake regulation characterized by excessive sleepiness and symptoms of dissociated rapid eye movement sleep (ie, sleep attacks, cataplexy, hypnagogic hallucinations, and sleep paralysis). With the exception of excessive sleepiness, which occurs in $100 \%$ of patients, symptoms vary both in frequency and severity among individuals with the disorder. Narcolepsy with cataplexy is the most common variant, with an estimated prevalence of $0.02 \%$ to $0.18 \%$ (Mignot 1998). Narcolepsy with cataplexy is associated with a deficiency of orexin-A, also known as hypocretin-1, a hypothalamic peptide implicated in energy homeostasis and arousal (Sakurai 2007).

\section{Chemistry and preclinical pharmacology}

Modafinil is a benzyhydrylsulfinylacetamide derivative with a molecular formula of $\mathrm{C}_{15} \mathrm{H}_{15} \mathrm{NO}_{2} \mathrm{~S}$. It is chemically unrelated to and pharmacologically distinguishable from the central nervous system (CNS) stimulants (eg, dextroamphetamine and methylphenidate) (Duteil et al 1990; Lin et al 1992, 1996; Simon et al 1994, 1995; Shelton et al 1995; Florence et al 2000). The primary pharmacological activity of modafinil is promoting wakefulness. Modafinil has been shown to increase wakefulness in studies conducted in animal models of narcolepsy (Shelton et al 1995) and 
sleep-disordered breathing (Panckeri et al 1996) and in sleepdeprived human volunteers (Lagarde et al 1995; Pigeau et al 1995; Walsh et al 2004).

Identification of the specific molecular targets that underlie the wake-promoting activity of modafinil is ongoing. In vitro, modafinil interacted negligibly or weakly with receptors for adenosine, dopamine, serotonin, histamine, melatonin, $\gamma$-amino butyric acid (GABA), and benzodiazepines (Mignot et al 1994; PROVIGIL ${ }^{\circledR}$ 2007). Modafinil has not been shown to be an $\alpha 1$-adrenergic agonist, although animal studies suggest an intact $\alpha 1$-adrenergic system may be necessary for modafinil-induced increases in locomotor activity (Duteil et al 1990; Hermant et al 1991; Lin et al 1992). In contrast to amphetamine, modafinil-induced wakefulness was not blocked by a dopamine-receptor antagonist or substantially affected by administration of an inhibitor of catecholamine synthesis (Lin et al 1992). In vitro, modafinil has been shown to bind weakly but selectively to the dopamine transporter (Mignot et al 1994; Nishino et al 1998; Madras et al 2006) and, to a lesser extent, the norepinephrine transporter (Madras et al 2006). Wake-promoting concentrations of modafinil increased extracellular levels of monoamines, including norepinephrine and dopamine, in certain rat brain regions (de Saint Hilaire et al 2001). Mutant mice lacking the dopamine transporter gene were unresponsive to modafinil (Wisor et al 2001). Studies in animals suggest modafinil increases activity in the cortex through selective actions on hypothalamic regions involved in regulating sleep and wakefulness. In a study that evaluated $c$-fos expression in cat brain, modafinil discretely and differentially from amphetamine and methylphenidate activated areas of the hypothalamus implicated in maintaining normal wakefulness, including the anterior hypothalamic nucleus and surrounding areas, with labeling of few cells in the cortex (Lin et al 1996). The authors suggested modafinil may promote wakefulness by disinihibiting cortical neurons. Another study reported intraperitoneal administration of wake-promoting doses of modafinil in rats induced $c$-fos expression in orexin neurons in the perifornical lateral hypothalamus and also increased $c$-fos in the tuberomammillary nucleus (TMN) of the posterior hypothalamus (Scammell et al 2000). The TMN is the source of central histaminergic neurons, which are active during waking and mediate cortical arousal (Lin et al 1988, 1990, 1994; Lin 2000). The study also reported modafinil decreased activity in the ventrolateral preoptic nucleus (VLPO), a sleep-promoting region of the hypothalamus. The VLPO is active during sleep and provides inhibitory GABA-ergic input to neurons involved in wakefulness (Sherin et al 1996, 1998; Gallopin et al 2000). Modafinil also increased activity in cortical regions, including the frontal and cingulate cortex, compared with controls. In another study, intracerebroventricular injection of modafinil increased histamine release in anesthetized rats whereas direct injection into the tuberomammillary nucleus did not, suggesting histaminergic neurons were not directly targeted (Ishizuka et al 2003). Others have shown modafinil may potentiate the sleep-inhibiting activity of noradrenaline in the VLPO (Gallopin et al 2004). These findings suggest modafinil may promote wakefulness, at least in part, by indirectly activating ascending arousal systems via an inhibitory action on sleep-active neurons (Gallopin et al 2004). This action is consistent the finding that modafinil is not associated with rebound hypersomnolence (Edgar and Seidel 1997; Lin et al 2000).

\section{Clinical pharmacokinetics}

Modafinil is a racemic compound, with two enantiomers that are pharmacokinetically dissimilar. The $R$-enantiomer has a longer half-life than the $S$-enantiomer (10-14 h vs 3-4 h) (Wong et al 1999a; Wong et al 1999b; Robertson and Hellriegel 2003), and the $S$-enantiomer has a faster rate of clearance (Wong et al 1999b). The enantiomers have similar pharmacological properties, but because total exposure of $R$-modafinil is approximately 3 times that of $S$ modafinil, wake-promoting activity is likely due primarily to the $R$-enantiomer (Dinges et al 2006). The $R$-enantiomer, also known as armodafinil, has recently been approved to treat excessive sleepiness associated with OSA, SWD, and narcolepsy (NUVIGIL ${ }^{\circledR}$ 2007), but is not yet commercially available. The effective elimination half-life of racemic modafinil allows once-daily dosing.

Orally administered modafinil is absorbed readily, with maximum plasma concentrations $\left(\mathrm{C}_{\max }\right)$ occurring at 2-4 hours (Robertson and Hellriegel 2003). Absorption ( $\left.\mathrm{t}_{\max }\right)$ may be delayed by approximately 1 hour if modafinil is taken with food (PROVIGIL 2007). Steady-state plasma concentrations are reached within 4 days of dosing (Robertson and Hellriegel 2003). Modafinil is well distributed in body tissue, with an apparent volume of distribution of $0.8 \mathrm{~L} / \mathrm{kg}$ (Wong et al 1999a). Metabolism (90\%) occurs primarily through the liver, with renal elimination of metabolites (Robertson and Hellriegel 2003). Less than $10 \%$ of the administered dose is excreted in urine as unchanged drug (Robertson and Hellriegel 2003). Two metabolites, modafinil acid and modafinil sulfone, reach appreciable levels in plasma (PROVIGIL ${ }^{\circledR}$ 2007; Robertson and Hellriegel 2003). Modafinil acid is 
the major urinary metabolite (Wong et al 1999a). Neither metabolite appears to contribute to the wake-promoting activity of modafinil (Robertson and Hellriegel 2003).

The pharmacokinetics of modafinil is not affected by gender, but oral clearance $(\mathrm{CL} / \mathrm{F})$ of modafinil may be reduced in elderly patients (Wong et al 1999b). Severe chronic renal failure was not shown to significantly affect the pharmacokinetics of modafinil, but plasma concentrations of an inactive metabolite increased 9-fold (PROVIGIL ${ }^{\circledR}$ 2007). In patients with cirrhosis of the liver, oral clearance of modafinil was decreased by $\sim 60 \%$, and steady state concentration was doubled compared with healthy subjects (PROVIGIL ${ }^{\circledR}$ 2007). Adjustments in dosing should be considered for these patient populations (Robertson and Hellriegel 2003; PROVIGIL ${ }^{\circledR}$ 2007).

\section{Drug - drug interactions}

Modafinil has the potential to modulate the activities of hepatic cytochrome P450 (CYP) isoenzymes. In human liver microsomes, modafinil reversibly inhibited CYP2C19 (Robertson et al 2000). Because of its potential to inhibit CYP2C19, modafinil may prolong elimination and increase circulating levels of drugs that are primarily metabolized via this enzyme (eg, diazepam, phenytoin, and propranolol). Dose reduction and toxicity monitoring may be required when drugs metabolized by CYP2C19 are coadministered with modafinil (Robertson et al 2000; RROVIGIL $^{\circledR} 2007$ ). In individuals who are deficient in CYP2D6, coadministration of modafinil with substrates of CYP2D6 that have ancillary routes of elimination through CYP2C19 (eg, tricyclic antidepressants and selective serotonin reuptake inhibitors) may lead to elevated circulating levels of these drugs and require dose adjustment (Robertson et al 2000; PROVIGIL ${ }^{\circledR}$ 2007). Modafinil suppressed CYP2C9 activity in cultures of human hepatocytes, suggesting a potential for drug interactions between modafinil and enzyme substrates (eg, $S$-warfarin, phenytoin) (Robertson et al 2000). Despite this in vitro finding, modafinil administration for 4 weeks did not significantly alter the pharmacokinetics of $S$-warfarin, a substrate for CYP2C9, compared with placebo in a study of healthy volunteers who were given a single dose of racemic warfarin following long-term administration of modafinil (Robertson et al 2002a). Because potential interactions between warfarin and other agents have also been documented, increased monitoring of prothrombin times/ International Normalized Ratio is recommended whenever modafinil and warfarin are coadministerered (Robertson et al 2000; PROVIGIL ${ }^{\circledR}$ 2007).
Modafinil also has been shown to cause a modest induction of CYP3A4, CYP2B6, and CYP1A2 in human hepatocytes (Robertson et al 2000). Protracted daily administration of modafinil $(400 \mathrm{mg}$ ) decreased systemic exposure of orally administered triazolam and ethinyl estradiol, two substrates of CYP3A4, suggesting increased elimination (Robertson et al 2002b). Dose adjustments may be necessary for patients taking these and similar medications (PROVIGIL ${ }^{\circledR} 2007$ ). Because the effectiveness of steroidal contraceptives may be reduced when taken concurrently with modafinil, additional or alternative methods of contraception should be used during treatment with modafinil and for 1 month after discontinuation of modafinil therapy (Robertson et al 2002b; PROVIGIL $^{\circledR}$ 2007).

Modafinil is partially metabolized by CYP3A4. Coadministration of potent inducers (eg, carbamazepine, phenobarbital, rifampin) or inhibitors (eg, ketoconazole, itraconazole) of this enzyme may modify modafinil levels in plasma (PROVIGIL ${ }^{\circledR}$ 2007).

\section{Clinical efficacy and tolerability: overview of double-blind placebo-controlled studies}

The efficacy and tolerability of once-daily doses (200-400 mg) of modafinil were established in largescale, double-blind, placebo-controlled clinical studies conducted in patients with OSA (Pack et al 2001; Black and Hirshkowitz 2005), SWD (Czeisler et al 2005; Erman et al 2007), and narcolepsy (US Modafinil in Narcolepsy Multicenter Study Group 1998, 2000). In five of the six studies, an objective measure of excessive sleepiness/ sleep latency - the Multiple Sleep Latency Test (MSLT) (Carskadon et al 1986) or the Maintenance of Wakefulness Test (MWT) (Mitler et al 1982; Doghramji et al 1997) - was chosen prospectively as a primary efficacy measure. The MSLT and MWT measure the propensity of individuals to fall asleep or remain awake, respectively, when instructed to do so in a formalized laboratory setting. Another primary end point was the investigator-rated change in overall clinical condition for severity of sleepiness (ie, the Clinical Global Impression of Change [CGI-C] [Guy 1976]). All six studies evaluated tolerability and safety of modafinil administered for 4-12 weeks.

The studies also evaluated subjectively determined sleepiness with the use of the Epworth Sleepiness Scale (ESS) (Johns et al 1991) or the Karolinska Sleepiness Scale (KSS) (Akerstedt et al 1982). The 8-item ESS was used in the OSA and narcolepsy studies to determine the extent to 
which excessive sleepiness interfered with daily activities. The 9-item KSS was used in a SWD study (Czeisler et al 2005) because of its widespread use in the assessment of excessive sleepiness in circadian rhythm sleep disorders. Other assessments included the Psychomotor Vigilance Task (PVT) (Dinges and Powell 1985), a test of sustained attention performance that was used to assess behavioral alertness (OSA and SWD studies); the Functional Outcomes of Sleep Questionnaire (FOSQ) (Weaver et al 1997), a self-administered 30-item instrument that was used to determine the effect of excessive sleepiness on functional status (OSA and SWD studies); and the 36-item Short Form Health Survey (SF-36) (Ware 2007), a self-administered questionnaire that assessed health-related quality of life (OSA, SWD, and narcolepsy studies). Patients with SWD completed electronic diaries that contained questions about sleepiness, sleep, and caffeine use during the night shift and on the commute home.

Patients enrolled in these studies had a diagnosis of OSA, SWD, or narcolepsy and were required to meet accepted criteria for excessive sleepiness. In the OSA studies, study drug was administered in conjunction with ongoing CPAP therapy. Patients were men and women (24-76 years) with a diagnosis of OSA and evidence of residual excessive sleepiness (ie, screening/baseline ESS score of $\geq 10$ ) despite CPAP use (ie, apnea-hypopnea index [AHI] of $<10$ ). In the 4-week study, 157 patients were randomly assigned to receive modafinil (week 1, $200 \mathrm{mg}$ /day; weeks 2-4, $400 \mathrm{mg}$ /day) or matching placebo once daily after the morning meal (Pack et al 2001). In the 12-week study, 309 patients were randomly assigned to receive modafinil $200 \mathrm{mg}$, modafinil $400 \mathrm{mg}$, or matching placebo once daily in the morning (Black and Hirshkowitz 2005). The starting dose was $100 \mathrm{mg}$, which was increased by $100-\mathrm{mg}$ increments every 2 days until the final dose was reached.

In the SWD studies, men and women (18-60 years) who were diagnosed with SWD and had excessive sleepiness during the night shift were eligible. In one of the studies, patients had to have a mean sleep latency of $\leq 6$ minutes on a night-time MSLT (Czeisler et al 2005). A total of 209 patients were randomly assigned to receive modafinil 200 mg once daily or placebo, taken 1 hour before the start of the night shift. In another 12-week study, 278 patients were randomized to receive modafinil $200 \mathrm{mg}$, modafinil $300 \mathrm{mg}$, or placebo 30-60 minutes before each night shift (Erman et al 2007).

In the narcolepsy studies, men and women (17-68 years) with a diagnosis of narcolepsy had sleep latencies of $\leq 8$ minutes (for those with recurrent daytime naps or lapses into sleep that were occurring almost daily for at least 3 months, with cataplexy) or $\leq 5$ minutes (for those with a complaint of excessive sleepiness or sudden muscle weakness, with sleep paralysis, hypnagogic hallucinations, automatic behaviors, and disrupted major sleep episode). Patients had to have 2 or more sleep-onset, rapid-eye-movement periods during administration of the MSLT. Patients $(n=285$ and $n=273)$ were randomly assigned to receive once-daily modafinil $200 \mathrm{mg} /$ day, modafinil $400 \mathrm{mg} /$ day, or placebo for 9 weeks using a rapid dose-titration schedule (US Modafinil in Narcolepsy Multicenter Study Group 1998) or a gradual step-up protocol (US Modafinil in Narcolepsy Multicenter Study Group 2000).

The 3 study populations were similar with regard to demographic characteristics (Table 1). There were proportionally more men than woman in the OSA studies, in keeping with the known epidemiology of the disorder. Most patients were rated as at least moderately ill with regard to sleepiness on the Clinical Global Impression of Severity. Patients were moderately to severely sleepy at baseline. In one study, mean sleep latency on the MSLT averaged approximately 2 minutes for patients with SWD (Czeisler et al 2005). In another study, mean sleep latency was 7.5 minutes for patients with OSA (Pack et al 2001). Sleep latencies of 5 minutes or less are indicative of severe sleepiness (Carskadon et al 1986; American Academy of Sleep Medicine 2001).

\section{Efficacy outcomes OSA studies}

In the 4-week study, modafinil significantly improved objectively determined wakefulness and reduced patientreported sleepiness (MSLT and ESS, respectively) compared with placebo (Table 2) (Pack et al 2001). At week 4, 51\% of patients receiving modafinil had excessive sleepiness that normalized (ie, ESS score <10) compared with $27 \%$ of patients receiving placebo $(\mathrm{p}<0.01)$. Significant improvements were shown for patients receiving modafinil compared with patients receiving placebo in 4 of 14 PVT performance variables, including the number of lapses (transformed) andthe median reaction time (Table 2) (Dinges and Weaver 2003). Modafinil improved functional status on the FOSQ, with significant improvements in the total score and 2 of 5 subscales (ie, activity and vigilance) versus placebo after 4 weeks. Modafinil significantly improved overall clinical condition for sleepiness, with $71 \%$ of patients receiving modafinil rated by the investigator as improved compared with $35 \%$ of patients receiving placebo $(\mathrm{p}<0.05)$ (Pack et al 2001). 
Table I Demographic characteristics and illness severity ratings at baseline for patients in large-scale, double-blind, placebo-controlled studies of modafinil

\begin{tabular}{|c|c|c|c|}
\hline & $\begin{array}{l}\text { Obstructive sleep apnea studies } \\
n=446^{a}\end{array}$ & $\begin{array}{l}\text { Shift work disorder studies } \\
n=455^{a}\end{array}$ & $\begin{array}{l}\text { Narcolepsy stud- } \\
\text { ies } n=530^{a}\end{array}$ \\
\hline Mean (SD) age, yr & $49.7(9.4)$ & $39.5(9.2)$ & $41.8(13.3)$ \\
\hline \multicolumn{4}{|l|}{ Gender, n (\%) } \\
\hline Male & $340(76)$ & $243(53)$ & $239(45)$ \\
\hline Female & $106(24)$ & $212(47)$ & $29 \mid(55)$ \\
\hline \multicolumn{4}{|l|}{ Race, n (\%) } \\
\hline White & $396(89)$ & $32 I(7 I)$ & $434(82)$ \\
\hline Black & $29(7)$ & $99(22)$ & $77(15)$ \\
\hline Other & $21(4)$ & $34(7)$ & $19(4)$ \\
\hline \multicolumn{4}{|l|}{ CGI-S rating } \\
\hline Not recorded & $43(10)$ & $0(0)$ & $0(0)$ \\
\hline Normal, mildly, or slightly ill & $|2|(27)$ & $0(0)$ & $91(17)$ \\
\hline Moderately ill & $199(45)$ & $280(62)$ & $237(45)$ \\
\hline Markedly, severely, or extremely ill & $83(19)$ & $175(38)$ & $202(38)$ \\
\hline
\end{tabular}

aPatients receiving one dose of study medication (modafinil or placebo) who had at least one post-baseline follow-up.

Adapted from Schwartz 2005.

Abbreviations: SD, standard deviation; CGI-S, clinical global impression of severity.

In the 12-week study, modafinil significantly improved objectively determined wakefulness on the MWT, reduced sleepiness levels on the ESS, and improved the FOSQ total score and subscale scores for vigilance, general productivity, and activity but not scores for social outcome or intimacy (Table 2) (Black and Hirshkowitz 2005). At week 12, overall clinical condition improved for $61 \%$ and $68 \%$ of patients receiving modafinil $200 \mathrm{mg}$ and $400 \mathrm{mg}$, respectively, compared with $37 \%$ of patients receiving placebo $(p<0.001)$ (Black and Hirshkowitz 2005).

\section{SWD studies}

In one 12-week study, modafinil $200 \mathrm{mg}$ significantly improved nighttime sleep latency on the MSLT, reduced levels of sleepiness on the KSS, and reduced the frequency of performance lapses on the PVT (Table 3) (Czeisler et al 2005). A greater proportion of patients receiving modafinil were rated as improved at the final visit on the CGI-C than patients receiving placebo $(74 \%$ vs $36 \%)$ ( $p<0.001)$. As reported in patient diaries, modafinil $200 \mathrm{mg}$ reduced the maximum level of sleepiness during night shift work compared with placebo (mean change from baseline, $-1.9[1.4]$ vs $-0.9[1.0])(p<0.001)$ and the level of sleepiness during the commute home $(-1.1[1.5]$ vs $-0.6[1.2])(p=0.01)$. Fewer patients receiving modafinil than placebo reported having accidents or near accidents on the commute home (29\% vs $54 \%)(\mathrm{p}<0.001)$. Modafinil was not associated with statistically significant effects on unintentional or intentional sleep episodes, caffeine intake, or mistakes, accidents, or near accidents during night shifts. During days following nights when the night shifts were not worked, no differences were reported in caffeine use or sleep efficiency between modafinil and placebo.

In another 12-week study, modafinil improved aspects of daily functioning and health-related quality of life the day after shifts compared with placebo (Table 3) (Erman et al 2007). The FOSQ total score was significantly improved with modafinil $300 \mathrm{mg}$, as were vigilance, activity, and productivity subscale scores. No significant improvement was shown with modafinil $300 \mathrm{mg}$ in social outcome or intimacy. Modafinil $200 \mathrm{mg}$ significantly improved the activity subscale score compared with placebo. Significant improvements were shown for the SF-36 mental component score and the vitality and role-emotional domain scores.

\section{Narcolepsy studies}

In both studies, modafinil 200 and $400 \mathrm{mg}$ significantly improved objectively determined sleep latency (MSLT and MWT) and subjectively assessed sleepiness levels (ESS) compared with placebo (Table 4) (US Modafinil in Narcolepsy Multicenter Study Group 1998, 2000). Modafinil significantly improved health-related quality of life on the SF-36 compared with placebo, with greater vitality, fewer constraints on daily activities due to physical or emotional limitations, and less interference with social activities due 


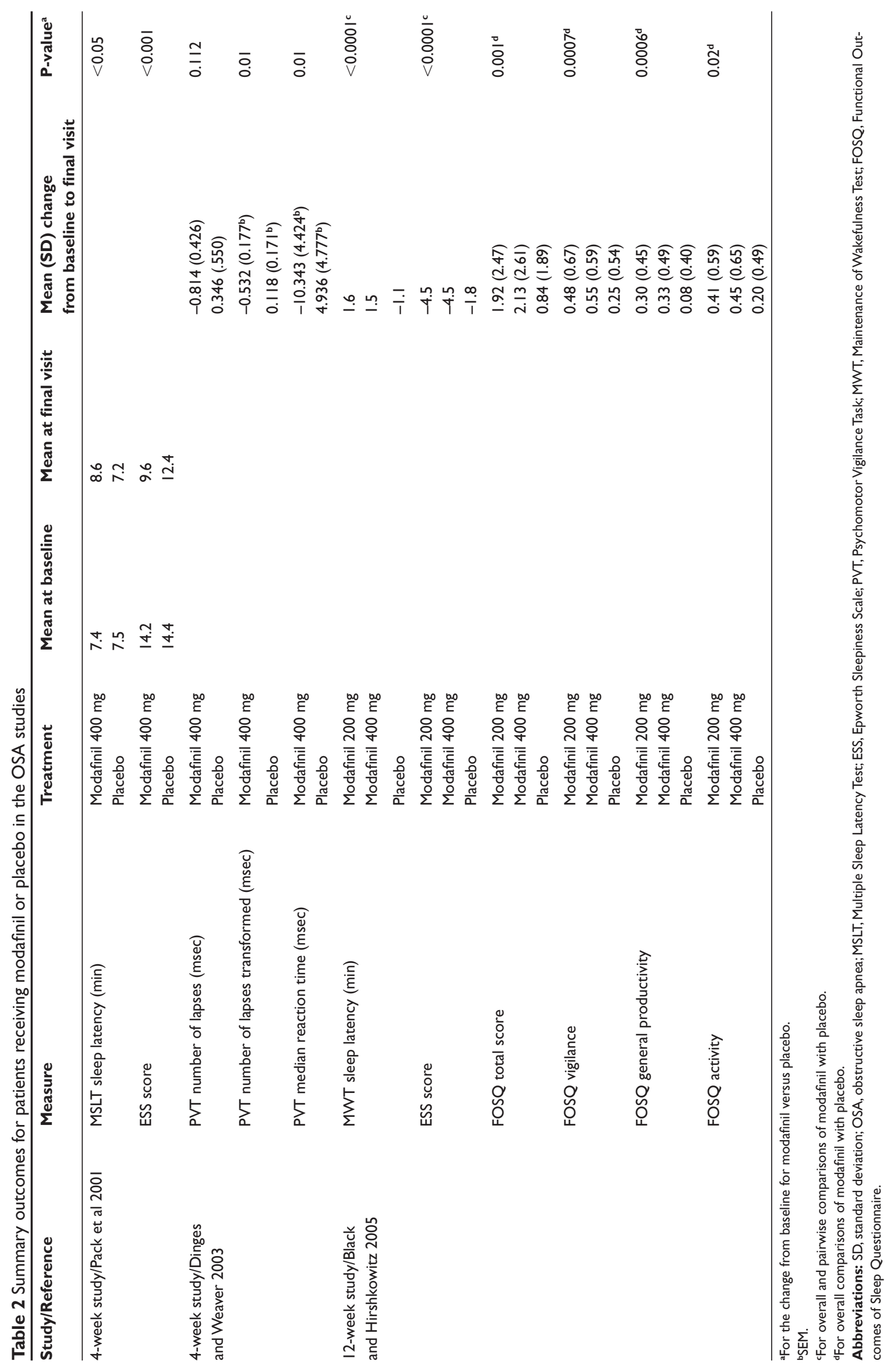


Table 3 Summary outcomes for patients receiving modafinil or placebo in the SWD studies

\begin{tabular}{|c|c|c|c|c|c|c|}
\hline Study/Reference & Measure & Treatment & $\begin{array}{l}\text { Mean (SD) } \\
\text { at baseline }\end{array}$ & $\begin{array}{l}\text { Mean (SD) } \\
\text { at final visit }\end{array}$ & $\begin{array}{l}\text { Mean (SD) change } \\
\text { from baseline } \\
\text { to final visit }\end{array}$ & P-value ${ }^{a}$ \\
\hline I2-week study \#|/ & MSLT sleep latency (min) & Modafinil $200 \mathrm{mg}$ & $2.07(0.2)$ & $3.77(0.5)$ & $1.7(0.4)$ & 0.002 \\
\hline \multirow[t]{5}{*}{ Czeisler et al 2005} & & Placebo & $2.04(0.2)$ & $2.37(0.3)$ & $0.3(0.3)$ & \\
\hline & KSS score & Modafinil $200 \mathrm{mg}$ & $7.3(0.1)$ & $5.8(0.2)$ & $-1.5(0.2)$ & $<0.001$ \\
\hline & & Placebo & $7.1(0.1)$ & $6.7(0.2)$ & $-0.4(0.2)$ & \\
\hline & PVT number of lapses & Modafinil $200 \mathrm{mg}$ & $12.50^{\mathrm{b}}$ & $10.25^{b}$ & $-2.6^{c}$ & $<0.001$ \\
\hline & & Placebo & $16.13^{b}$ & $23.75^{b}$ & $3.8^{c}$ & \\
\hline |2-week study \#2/ & FOSQ total score ${ }^{d}$ & Modafinil $300 \mathrm{mg}$ & & & 2.3 & $<0.05$ \\
\hline \multirow[t]{17}{*}{ Erman et al 2007} & & Placebo & & & 1.6 & \\
\hline & FOSQ vigilance & Modafinil $300 \mathrm{mg}$ & & & 0.6 & $<0.05$ \\
\hline & & Placebo & & & 0.4 & \\
\hline & FOSQ activity & Modafinil $200 \mathrm{mg}$ & & & 0.5 & $<0.05$ \\
\hline & & Placebo & & & 0.3 & \\
\hline & & Modafinil $300 \mathrm{mg}$ & & & 0.5 & $<0.01$ \\
\hline & & Placebo & & & 0.3 & \\
\hline & FOSQ productivity & Modafinil $300 \mathrm{mg}$ & & & 0.4 & $<0.01$ \\
\hline & & Placebo & & & 0.3 & \\
\hline & SF-36 mental component score ${ }^{e}$ & Modafinil $200 \mathrm{mg}$ & & & 3.7 & $<0.05$ \\
\hline & & Modafinil $300 \mathrm{mg}$ & & & 3.2 & $<0.05$ \\
\hline & & Placebo & & & 0.7 & \\
\hline & SF-36 vitality & Modafinil $200 \mathrm{mg}$ & & & 15.0 & $<0.001$ \\
\hline & & Modafinil $300 \mathrm{mg}$ & & & 14.8 & $<0.0001$ \\
\hline & & Placebo & & & 5.3 & \\
\hline & SF-36 role emotional & Modafinil $300 \mathrm{mg}$ & & & 4.3 & $<0.05$ \\
\hline & & Placebo & & & -2.9 & \\
\hline
\end{tabular}

${ }^{\text {a}}$ For the change from baseline for modafinil versus placebo.

bMedian number of lapses.

cMedian change from baseline.

dFOSQ total scores at baseline were similar for modafinil $200 \mathrm{mg}$, modafinil $300 \mathrm{mg}$, and placebo (range: I4.3-I4.7 points).

eSF-36 mental component scores at baseline were similar for the 3 groups (range: 45.3-47.4).

Abbreviations: SD, standard deviation; SWD, shift work disorder; MSLT, Multiple Sleep Latency Test; PVT, Psychomotor Vigilance Task; KSS, Karolinska Sleepiness Score;

FOSQ, Functional Outcomes of Sleep Questionnaire; SF-36, 36-item Short Form Health Survey.

to health (Table 4) (Beusterien et al 1999). No significant treatment effect was shown for physical functioning, bodily pain, general health, or mental health.

\section{Tolerability and safety outcomes}

In these double-blind placebo-controlled studies, 1501 patients received 200, 300, or $400 \mathrm{mg}$ of modafinil $(\mathrm{n}=934)$ or placebo $(n=567)$ for up to 12 weeks (Roth et al 2007). Safety was assessed in these studies by monitoring adverse events, vital signs (ie, resting systolic and resting diastolic blood pressures, heart rate, and body weight), electrocardiogram (ECG) intervals, clinical laboratory parameters, and polysomnographic parameters collected during the day (OSA and narcolepsy) or night (SWD). Across the studies, adverse event profiles were similar, with headache (34\%), nausea (11\%), infection $(10 \%)$, nervousness $(7 \%)$, rhinitis $(7 \%)$, diarrhea (6\%), back pain (6\%), anxiety (5\%), dizziness, $(5 \%)$, dyspepsia (5\%), and insomnia (5\%) the most common treatment-emergent adverse events ( Roth et al 2007). Headache was considered to be dose related (Roth et al 2007). Adverse events that occurred more frequently with modafinil than placebo were headache, nausea, nervousness, anxiety, insomnia, anorexia, dry mouth, hypertension, and pharyngitis $(\mathrm{p}<0.05$ vs placebo) (Roth et al 2007). Most adverse events (nearly $90 \%$ ) occurred during the first month and were considered by the investigator to be mild to moderate in nature (PROVIGIL ${ }^{\circledR}$ 2007; Roth et al 2007). For the combined modafinil group, the cumulative incidence of headache was $20 \%$ at week 1 (vs $9 \%$ for placebo), $29 \%$ at month 1 (vs 18\% for placebo), and 34\% at month 3 (vs 23\% for placebo) (Roth et al 2007). Across the studies, $8 \%$ of patients receiving modafinil discontinued because of an adverse event compared with $3 \%$ of patients receiving placebo (PROVIGIL ${ }^{\circledR} 2007$; Roth et al 2007). The most frequently occurring adverse event associated with discontinuation was headache (2\%) (Roth et al 2007).

Although a small but statistically significant difference in the mean change from baseline in sitting systolic blood pressure was observed between modafinil and placebo in the 
Table 4 Summary outcomes for patients receiving modafinil or placebo in the narcolepsy studies

\begin{tabular}{|c|c|c|c|c|c|c|}
\hline Study/Reference & Measure & Treatment & $\begin{array}{l}\text { Mean (SD) } \\
\text { at baseline }\end{array}$ & $\begin{array}{l}\text { Mean (SD) } \\
\text { at final visit }\end{array}$ & $\begin{array}{l}\text { Mean (SD) change } \\
\text { from baseline } \\
\text { to final visit }\end{array}$ & P-value ${ }^{a}$ \\
\hline \multicolumn{7}{|l|}{ 9-week study \#I/ US } \\
\hline \multicolumn{7}{|c|}{ Modafinil in Narcolepsy } \\
\hline Multicenter Study & MSLT sleep latency (min) & Modafinil $200 \mathrm{mg}$ & $2.9(2.5)$ & $4.7(4.4)$ & & $<0.001$ \\
\hline \multirow[t]{8}{*}{ Group 1998} & & Modafinil $400 \mathrm{mg}$ & $3.3(2.9)$ & $5.2(4.5)$ & & $<0.001$ \\
\hline & & Placebo & $2.8(2.2)$ & $3.3(3.2)$ & & \\
\hline & MWT sleep latency (min) & Modafinil $200 \mathrm{mg}$ & $5.8(5.0)$ & $8.1(6.1)$ & & $<0.001$ \\
\hline & & Modafinil $400 \mathrm{mg}$ & $6.6(5.2)$ & $8.9(6.2)$ & & $<0.001$ \\
\hline & & Placebo & $5.8(4.7)$ & $5.1(4.7)$ & & \\
\hline & ESS score & Modafinil $200 \mathrm{mg}$ & $17.9(3.8)$ & $14.4(5.7)$ & & $<0.001$ \\
\hline & & Modafinil $400 \mathrm{mg}$ & I7.I (4.2) & $13.0(5.7)$ & & $<0.001$ \\
\hline & & Placebo & $18.3(3.3)$ & I7.| (5.0) & & \\
\hline \multicolumn{7}{|l|}{ 9-week study \#2/ US } \\
\hline \multicolumn{7}{|c|}{ Modafinil in Narcolepsy } \\
\hline Multicenter Study & MSLT sleep latency (min) & Modafinil $200 \mathrm{mg}$ & $3.0(2.2)$ & $4.9(4.3)$ & & $<0.001$ \\
\hline \multirow[t]{8}{*}{ Group 2000} & & Modafinil $400 \mathrm{mg}$ & $2.7(2.0)$ & $5.1(4.0)$ & & \\
\hline & & Placebo & $2.2(1.8)$ & $3.5(3.4)$ & & \\
\hline & MWT sleep latency (min) & Modafinil $200 \mathrm{mg}$ & $6.1(4.9)$ & $8.2(5.9)$ & & 0.001 \\
\hline & & Modafinil $400 \mathrm{mg}$ & $5.9(4.4)$ & $7.8(5.3)$ & & $<0.001$ \\
\hline & & Placebo & $6.0(5.0)$ & $5.5(4.5)$ & & \\
\hline & ESS score & Modafinil $200 \mathrm{mg}$ & $17.4(3.8)$ & $13.0(5.1)$ & & $<0.001$ \\
\hline & & Modafinil $400 \mathrm{mg}$ & $18.0(3.4)$ & $12.3(5.1)$ & & $<0.001$ \\
\hline & & Placebo & $17.6(4.0)$ & $15.8(4.8)$ & & \\
\hline \multicolumn{7}{|l|}{$\begin{array}{l}\text { 9-week studies } \\
\text { combined/Beusterien }\end{array}$} \\
\hline \multirow[t]{12}{*}{ et al 1999} & SF-36 vitality & Modafinil $200 \mathrm{mg}$ & & & 11 & $<0.05$ \\
\hline & & Modafinil $400 \mathrm{mg}$ & & & 13 & $<0.05$ \\
\hline & & Placebo & & & 3 & \\
\hline & SF-36 role limitations- & Modafinil $200 \mathrm{mg}$ & & & 6 & \\
\hline & emotional & Modafinil $400 \mathrm{mg}$ & & & 10 & $<0.05$ \\
\hline & & Placebo & & & -1 & \\
\hline & SF-36 role limitations- & Modafinil $200 \mathrm{mg}$ & & & 14 & $<0.05$ \\
\hline & physical & Modafinil $400 \mathrm{mg}$ & & & 20 & $<0.05$ \\
\hline & & Placebo & & & 6 & \\
\hline & SF-36 social function & Modafinil $200 \mathrm{mg}$ & & & 6 & \\
\hline & & Modafinil $400 \mathrm{mg}$ & & & 11 & $<0.05$ \\
\hline & & Placebo & & & 2 & \\
\hline
\end{tabular}

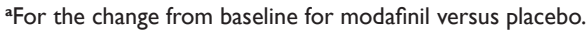

Abbreviations: SD, standard deviation; MSLT, Multiple Sleep Latency Test; MWT, Maintenance of Wakefulness Test; ESS, Epworth Sleepiness Scale.

4-week OSA study (Pack et al 2001), no significant changes from baseline to final visit in mean systolic blood pressure, diastolic blood pressure, or heart rate were shown between modafinil and placebo for the combined OSA studies or the combined SWD studies (Roth et al 2007). In the combined narcolepsy studies, a significant between-group difference in heart rate and blood pressure was demonstrated; the difference was attributable to a greater change from baseline for placebo than modafinil (Roth et al 2007). A greater proportion of patients receiving modafinil began treatment with or increased their use of antihypertensive medications compared with patients receiving placebo ( $2.4 \%$ vs $0.7 \%)$ (PROVIGIL ${ }^{\circledR}$ 2007; Roth et al 2007). When OSA data alone were included, $3.4 \%$ versus $1.1 \%$ of patients receiving modafinil or placebo, respectively, required changes in the use of antihypertensive medications (PROVIGIL ${ }^{\circledR}$ 2007; Roth et al 2007). For some patients, increased blood pressure monitoring may be necessary.

Across the studies, no significant changes from baseline were shown in mean body weight. Clinically significant decreases in weight (ie, $\geq 7 \%$ from baseline) were reported for 3\% of patients receiving modafinil (Roth et al 2007). No treatment-emergent pattern of electrocardiographic abnormalities was found following modafinil administration (PROVIGIL ${ }^{\circledR}$ 2007; Roth et al 2007). Mean plasma levels of gamma glutamyltransferase and alkaline phosphatase were 
higher following administration of modafinil but not placebo (PROVIGIL ${ }^{\circledR}$ 2007; Roth et al 2007). Clinically significant abnormalities in laboratory parameters were rare and reported in $<1 \%$ of patients receiving modafinil or placebo (Roth et al 2007).

In these studies, modafinil did not adversely affect scheduled sleep. No clinically meaningful or statistically significant differences shown between groups in polysomnographically determined sleep parameters, including sleep efficiency, sleep duration, and stages of sleep (US Modafinil in Narcolepsy Multicenter Study Group 1998, 2000; Pack et al 2001; Black and Hirshkowitz 2005, Czeisler et al 2005). In the 4-week OSA study, mean arousal index (ie, the number of arousals per hour of sleep) was slightly greater for patients receiving modafinil than patients receiving placebo (14.3 vs 11.8) ( $\mathrm{p}=0.018$ ) (Pack et al 2001). In a 9-week narcolepsy study, sleep efficiency was slightly better for the modafinil 200-mg group than the placebo group (US Modafinil in Narcolepsy Multicenter Study Group 2000). Modafinil was not associated with symptoms of withdrawal (eg, fatigue, agitation, vivid dreams, hypersomnia, or increased appetite) when its use was discontinued for 2 weeks following 9 weeks of administration in patients with narcolepsy (US Modafinil in Narcolepsy Multicenter Study Group 2000).

\section{Additional safety data}

More than 3500 patients have been evaluated for safety in clinical studies of modafinil for treatment of excessive sleepiness associated with OSA, SWD, and narcolepsy (Schwartz 2005; PROVIGIL ${ }^{\circledR}$ 2007). The type and incidence of adverse events have been consistent with those reported in the placebo-controlled trials. Serious rash requiring hospitalization and treatment discontinuation have been reported in association with modafinil use (FDA 2007; PROVIGIL ${ }^{\circledR}$ 2007). In worldwide postmarketing experience, rare cases (exceeding the background incidence rate in the general population of 1-2 cases per million-person years) of serious or life-threatening rash, including Stevens-Johnson Syndrome, have been reported in adults and children. No factors are known that may be used to predict either rash occurrence or severity. It is recommended that modafinil be discontinued at the first sign of rash unless the rash is clearly not related to the drug.

\section{Extension studies}

An open-label extension of the 4-week OSA study reported improvements in wakefulness and sleep-related functional status were maintained for 12 additional weeks in patients receiving CPAP therapy (Schwartz et al 2003c). In a long-term open-label extension conducted in patients who participated in the 12-week OSA study, improvements in subjectively determined wakefulness, functional status, and health-related quality of life were maintained with modafinil for 12 months (Schwartz 2005; Hirshkowitz and Black 2007). The extension study did not evaluate objectively determined sleep latency. Modafinil continued to be well tolerated, with infection (11.3\%), headache (9.4\%), and nervousness $(9.0 \%)$ being the most common adverse events reported (Hirshkowitz and Black 2007). Although no substantial alterations were reported in the mean change from baseline in blood pressure and heart rate, a clinically significant elevation in blood pressure was reported for 6 patients $(2 \%)$ (at a single evaluation for 5 patients and at 2 consecutive evaluations for 1 patient). Five of these patients had a history of hypertension.

Patients from the narcolepsy studies participated in open-label extensions in which they received modafinil $200 \mathrm{mg}$ to $400 \mathrm{mg}$ once daily (Mitler et al 2000; Schwartz 2005). Improvements in wakefulness with modafinil were maintained through 136 weeks of open-label administration. Modafinil was well tolerated, with a low likelihood for the development of tolerance.

\section{Additional clinical studies}

In addition to the large-scale placebo-controlled studies and long-term extension studies, other clinical studies and case reports have reported improvements in wakefulness with modafinil in patients with OSA (Kingshott et al 2001; Schwartz et al 2003c) and narcolepsy (Billiard et al 1994; Besset et al 1996; Broughton et al 1997; Moldofsky et al 2000; Thorpy et al 2003; Schwartz et al 2003a, b, 2004, 2005). In a double-blind crossover study of 30 patients with OSA who were receiving CPAP therapy, modafinil had no effect on sleepiness as assessed on the MSLT or the ESS but significantly improved wakefulness on the MWT (Kingshott et al 2000). In patients with narcolepsy, a 24-week study which included three 2 -week double-blind crossover periods, a 16-week open-label period, and a 2-week placebocontrolled discontinuation period reported improvements in objectively determined wakefulness and subjective sleepiness that were comparable to improvements shown in the 9-week double-blind narcolepsy studies (Broughton et al 1997; Moldofsky et al 2000).

\section{Dosing}

The recommended dose of modafinil is $200 \mathrm{mg}$, to be taken once daily in the morning for patients with OSA 
or narcolepsy, or approximately 1 hour before the start of the work shift for patients with SWD (PROVIGIL ${ }^{\circledR}$ 2007). Once daily doses of up to $400 \mathrm{mg}$ have been well tolerated in randomized placebo-controlled studies. However, in the 9-week studies of narcolepsy patients, the 400-mg dose did not provide any benefit beyond that shown for the 200-mg dose (US Modafinil in Narcolepsy Multicenter Study Group 1998, 2000). While no clear dose response was observed in these placebo-controlled studies, a double-blind crossover study $(\mathrm{n}=32)$ subsequently showed modafinil $400 \mathrm{mg}$, taken once daily or as a split dose in the morning and at midday, was significantly better at promoting wakefulness throughout the entire day than modafinil $200 \mathrm{mg}$ taken once-daily in the morning (both $\mathrm{p}<0.05$ ) (Schwartz et al 2003b). The different findings between the placebo-controlled studies and the crossover and parallel studies likely reflect, at least in part, methodological differences in the execution and timing of sleep latency (MWT) testing protocols.

Dose-response effects were confirmed and expanded in a subsequent analysis of 2 double-blind parallel group studies conducted in patients with narcolepsy $(n=56)$ (Schwartz et al 2005). Modafinil (200 mg once daily, $400 \mathrm{mg}$ once daily, 400 $\mathrm{mg}$ split-dose, and $600 \mathrm{mg}$ split-dose) significantly improved patients' ability to sustain wakefulness compared with baseline in a dose-dependent manner $(\mathrm{p}<0.05)$, with split-dose regimens producing significantly greater improvement in MWT sleep latency than once-daily regimens in the afternoon and evening. These studies utilized an extended-day MWT, assessing the ability to remain awake at 2-hour intervals from 9 am to $9 \mathrm{pm}$. Another study showed modafinil 600 mg taken as split dose was significantly more effective than modafinil $400 \mathrm{mg}$ once daily in improving late-day MWT sleep latency in patients with narcolepsy $(n=24)$ (Schwartz et al 2004). Others have reported modafinil taken as a split dose in the morning and at midday (300-500 mg) did not adversely affect the quantity or quality of nighttime sleep in placebo-controlled, crossover studies (Billiard et al 1994; Broughton et al 1997; Moldofsky et al 2000). Dose escalation or split-dose regimens may be important for patients who have satisfactory responses to modafinil in the morning and afternoon but experience excessive sleepiness in the late afternoon or evening.

\section{Abuse potential}

Modafinil is listed in Schedule IV of the Controlled Substances Act (PROVIGIL ${ }^{\circledR}$ 2007) because its potential for abuse is relatively low and may lead to limited physical or psychological dependence. In one preclinical study, the reinforcing and stimulant-discriminative effects of modafinil were approximately 250 times less potent than amphetamine (Gold and Balster 1996). Another preclinical study reported modafinil did not produce reinforcing or rewarding effects in stimulant-naïve animals (Deroche-Gamonet et al 2002). In clinical studies conducted in healthy volunteers with no current or past history of substance abuse (Warot et al 1993) and in volunteers with histories of illicit drug use (Jasinski 2000; Rush et al 2002a, b), modafinil could be distinguished from CNS stimulants on the basis of subjective effects (eg, elation or euphoria). Postmarketing surveillance (over 4 years) has found no generalized misuse of modafinil, suggesting its potential for abuse on a large scale is limited (Myrick et al 2004).

\section{Therapeutic considerations and clinical implications}

Identification of the underlying causes of excessive sleepiness, including any sleep disorders, is critical to its successful management. Persistent or severe sleepiness that interferes with daily function and poses undue health burdens or safety risks may require pharmacologic therapy. Modafinil may be prescribed for patients who have been evaluated for excessive sleepiness and have a diagnosis of OSA, SWD, or narcolepsy.

Across large-scale, double-blind studies, placebocontrolled studies, modafinil significantly improved sleep latency on the MSLT and ability to maintain wakefulness on the MWT, improved overall clinical condition for sleepiness severity, and reduced patient-reported sleepiness on the ESS and KSS. Improvements in wakefulness were accompanied by improvements in behavioral alertness, functional status, and health-related quality of life. Modafinil was well tolerated in the double-blind placebo-controlled studies and long-term studies. Noteworthy was the finding that modafinil did not elevate mean blood pressure or heart rate relative to placebo in populations at risk for cardiovascular morbidity (ie, patients with OSA [Nieto et al 2000; Peppard et al 2000; ] and night shift workers [Kawachi et al 1995; Tenkanen et al 1997]) (Roth et al 2007).

The MSLT and MWT were primary measures of efficacy in the double-blind placebo-controlled studies. As objective measures of sleep latency, the MSLT and the MWT are used in research and clinical settings. Of the two, the MSLT is used more widely and is considered to be a standard test for sleepiness by most sleep medicine specialists (Wise 2006). The strengths and weaknesses of the MSLT and MWT have been described in a recent review that evaluated their clinical 
usefulness (Arand et al 2005). While these tests do not appear to adequately discriminate between patients with sleep disorders and control subjects due in part to floor (MSLT) and ceiling (MWT) effects and to large standard deviations (Arand et al 2005), they effectively monitor changes caused by interventions that alter sleepiness or alertness (Arand et al 2005). The MSLT in particular appears to be sensitive to changes in sleepiness across the 24-hour day and following long-term sleep debt or extension (Seidel et al 1984; Roehrs et al 1996). In addition, sleep latencies have been shown to reflect circadian changes in studies that simulated night shift conditions (Arand et al 2005), suggesting responses occur as expected when sleep cycles are reversed (eg, for night shift workers). Whether establishing a diagnosis or evaluating a response to treatment, sleep latency test findings should be interpreted within the context of other available medical information and testing (Arand et al 2005).

OSA is a common cause of excessive sleepiness, and residual sleepiness occurs in some patients who are otherwise well treated for the underlying airway obstruction (Weaver et al 2007). While modafinil reduces residual sleepiness in these patients, it does not treat the cause of OSA. It is therefore critical that patients adhere to interventions that directly address OSA-related pathology, such as CPAP therapy (Hirshkowitz and Black 2007). Weaver and colleagues established a relationship between hours of CPAP use during the night and achieving normal levels of daytime sleepiness and functioning; for example, thresholds above which further improvements were less likely for ESS was 4 hours, MSLT was 6 hours, and FOSQ was 7.5 hours (Weaver et al 2007). Despite concerns to the contrary (Pollak 2003), modafinil does not appear to adversely affect CPAP use. While a statistically significant 12-minute reduction in nightly CPAP use was shown for patients receiving modafinil compared with patients receiving placebo in a 7-week, placebo-controlled crossover study of 30 patients (Kingshott et al 2000), modafinil did not significantly alter CPAP use in the large-scale, 4-week and 12-week doubleblind studies (Pack et al 2001; Black and Hirshkowitz 2005). In a 12-month follow-up to the 12-week study, mean nightly CPAP use declined by 34 minutes $(p<0.0001$ for the change from baseline) to a final visit duration of 5.4 hours (Hirshkowitz and Black 2007). This duration is within the range of previously reported values for long-term CPAP use (4.3-6.5 hours) (Engleman et al 1994b; Reeves-Hoche et al 1994; Krieger et al 1996; Pieters et al 1996; Collard et al 1997). As a precaution, CPAP use should be encouraged and periodically assessed (Black and Hirshkowitz 2007;
PROVIGIL $^{\circledR}$ 2007). Difficulties with CPAP use, such as inadequate CPAP pressure and microarousals and sleep disruption caused by wearing the CPAP apparatus, should be addressed (Hirshkowitz and Black 2007).

Given the large number of individuals who work night shifts on a rotating or permanent basis or work early morning shifts (Beers 2000), recognition and diagnosis of SWD remains a pressing clinical issue. The adverse consequences of shift work may be limited to those individuals who show a differential vulnerability to the effects of sleep loss (Drake et al 2004; Van Dongen et al 2004). Such individuals may be predisposed to developing SWD. Patients with SWD appear to be as sleepy during the night as patients with narcolepsy are during the day. Mean improvements with modafinil in MSLT sleep latency in patients with SWD were similar in magnitude to improvements reported for patients with narcolepsy who were treated with modafinil (US Modafinil in Narcolepsy Multicenter Study Group 1998, 2000) and to improvement reported in a meta-analysis of studies conducted in patients with OSA who were treated with CPAP therapy ( 0.74 min more than placebo) (Patel et al 2003). Although sleep latency was improved by nearly 2 minutes, it averaged less than 5 minutes during the night, below what is considered to be normal during the daytime (Czeisler et al 2005). Similarly, mean sleep latencies have been reported to improve but not to normalize completely in patients with narcolepsy, either with modafinil or CNS stimulants (US Modafinil in Narcolepsy Multicenter Study Group 1998; Mitler 1991). Despite the lack of normalization, improvements across objective and subjective measures, including those for sleepiness, overall clinical condition, and behavioral alertness (Czeisler et al 2005), together with improvements in functional status and health-related quality of life (Erman et al 2007) and diary data that showed proportionally fewer patients reporting accidents or near accidents (Czeisler et al 2005), suggest modafinil administration is associated with clinically meaningful improvement in these patients. Because modafinil may not completely eliminate excessive sleepiness in all patients, individuals should be advised to avoid activities that are potentially dangerous (eg, driving or operating machinery) or require appropriate levels of wakefulness until and unless modafinil affords sufficient wakefulness (PROVIGIL ${ }^{\circledR}$ 2007).

Modafinil is an established first-line therapy for excessive sleepiness in patients with narcolepsy (Black et al 2005; Billiard et al 2006). An evaluation of adverse events and the potential for abuse must be made on an individual basis 
when prescribing modafinil or other therapies for excessive sleepiness.

\section{Conclusions}

Multiple clinical studies indicate modafinil is an efficacious and well-tolerated therapy in the clinical management of excessive sleepiness in patients with OSA with ongoing sleepiness despite CPAP therapy, SWD, and narcolepsy. Long-term studies suggest continued efficacy, with a low likelihood of tolerance and no adverse effects on scheduled sleep. Abuse liability studies show a limited potential for abuse.

\section{Disclosures}

The author has served as a consultant and/or speaker for AstraZeneca, Boehringer Ingelheim, Cephalon, GSK, Jazz, Medpointe, Pfizer, Resmed, and Takeda.

\section{References}

Akaoka H, Roussel B, Lin JS, et al. 1991. Effect of modafinil and amphetamine on the rat catecholaminergic neuron activity. Neurosci Lett, 123:20-2.

Akerstedt T, Torsvall L, Gillberg M. 1982. Sleepiness and shift work: field studies. Sleep, 5(suppl 2):S95-S106.

American Academy of Sleep Medicine. 2001. International classification of sleep disorders: diagnostic and coding manual. Westchester, IL: American Academy of Sleep Medicine.

Arand D, Bonnet M, Hurwitz T, et al. 2005. The clinical use of the MSLT and MWT. Sleep, 28:123-44.

BaldwinCM, Vishesh KK, Holberg CJ, et al. 2004. Associations between gender and measures of daytime somnolence in the Sleep Heart Health Study. Sleep, 27:305-11.

Beers TM. 2000. Flexible schedules and shift work: replacing the ' 9 to 5' workday? Monthly Labor Rev, 123:33-40.

Besset A, Chetrit M, Carlander B et al. 1996. Use of modafinil in the treatment of narcolepsy: a long-term follow-up study. Neurophysiol Clin, 26:60-6.

Beusterien KM, Rogers AE, Walsleben JA, et al. 1999. Health-related quality of life effects of modafinil for treatment of narcolepsy. Sleep, 22:757-64.

Billiard M, Bassetti C, Dauvilliers Y, et al. 2006. EFNS guidelines on management of narcolepsy. Eur J Neurol, 13:1035-48.

Billiard M, Besset A, Montplaisir J, et al. 1994. Modafinil: a double-blind multicentric study. Sleep, 17:S107-S12.

Black JE, Hirshkowitz M. 2005. Modafinil for treatment of residual excessive sleepiness in nasal continuous positive airway pressure-treated obstructive sleep apnea/hypopnea syndrome. Sleep, 28:464-71.

Black JE, Brooks SN, Nishino S. 2005. Conditions of primary excessive daytime sleepiness. Neurol Clin, 23:1025-44.

Broughton RJ, Fleming JAE, George CFP, et al.1997. Randomised, doubleblind, placebo-controlled crossover trial of modafinil in the treatment of excessive daytime sleepiness in narcolepsy. Neurology, 49:444-51.

Carskadon MA, Dement WC, Mitler MM, et al. 1986. Guidelines for the multiple sleep latency test (MSLT): a standard measure of sleepiness. Sleep, 9:519-624.

Collard P, Pieters T, Aubert G, et al. 1997. Compliance with nasal CPAP in obstructive sleep apnea patients. Sleep Med Rev, 1:33-44.

Czeisler CA, Dinges DF, Walsh JK, et al. 2005. Modafinil for excessive sleepiness associated with shift-work sleep disorder. 2005. $N$ Engl J Med, 353:476-86. de Saint Hilaire Z, Orosco M, Rouch C, et al. 2001. Variations in extracellular monoamines in the prefrontal cortex and medial hypothalamus after modafinil administration: a microdialysis study in rats. Neuroreport, 12:3533-7.

Deroche-Gamonet V, Darnaudery M, Bruin-Slot L, et al. 2002. Study of the addictive potential of modafinil in naïve and cocaine-experienced rats. Psychopharmacology (Berl), 161:387-95.

Dinges DF. 1995. An overview of sleepiness and accidents. J Sleep Res, 4(suppl 2):4-14.

Dinges DF, Arora S, Darwish M, et al. 2006. Pharmacodynamic effects on alertness of single doses of armodafinil in healthysubjects during a nocturnal period of acute sleep loss. Curr Med Res Opin, 22:159-67.

Dinges DF, Powell JW. 1985. Microcomputer analyses of performance on a portable, simple visual RT task during sustained operations. Behav Res Methods Instrum Comput, 17:652-5.

Dinges DF. Weaver TE. 2003. Effects of modafinil on sustained attention performance and quality of life in OSA patients with residual sleepiness while being treated with nCPAP. Sleep Medicine, 4:393-402.

Doghramji K, Mitler MM, Sangal BB, et al. A normative study of the maintenance of wakefulness test (MWT). Electroencephalogr Clin Neurophysiol, 103:554-62.

Drake CL, Roehrs T, Richardson G, et al. 2004. Shift work sleep disorder: prevalence and consequences beyond that of symptomatic day workers. Sleep, 27:1453-62.

Duteil J, Rambert F, Pessonnier J, et al. 1990. Central $\alpha 1$-adrenergic stimulation in relation to the behavior stimulating effect of modafinil; studies with experimental animals. Eur J Pharmacol, 180:49-58.

Edgar DM, Seidel WF. 1997. Modafinil induces wakefulness without intensifying motor activity or subsequent rebound hypersomnolence in the rat. J Pharmacol Exp Ther, 283:757-69.

Engleman HM, Martin SE, Deary IJ, Douglas NJ. 1994a. Effect of continuous positive airway pressure treatment on daytime function in sleep apnoea/hypopnoea syndrome. Lancet, 343:572-5.

Engleman HM, Martin SE, Douglas NJ. 1994b. Compliance with CPAP therapy in patients with the sleep apnoea/hypopnoea syndrome. Thorax, 49:263-6.

Erman MK, Rosenberg R. Modafinil for excessive sleepiness associated with chronic shift work sleep disorder: effects on patient functioning and health-related quality of life. 2007 Care Companion J Clin Psychiatry, 9:188-94.

[FDA] Food and Drug Administration. 2007. Drug Safety Newsletter. Accessed 7 October 2007. URL: http://www.fda.gov/cder/dsn/2007_ fall/postmarketing.htm.

Florence G, Bonnier R, Plagnes D, et al. 2000. Effect of modafinil on cerebral blood flow on anesthetized rats: comparison with amphetamine. Exp Brain Res, 135:552-6.

Gale SD, Hopkins RO. 2004. Effects of hypoxia on the brain: neuroimaging and neuropsychological findings following carbon monoxide poisoning and obstructive sleep apnea. J Int Neuropsychol Soc, 10:60-71.

Gallopin T, Fort P, Eggermann E, et al. 2000. Identification of sleeppromoting neurons in vitro. Nature, 404:992-5.

Gallopin T, Luppi PH, Rambert FA, et al. 2004. Effect of the wake-promoting agent modafinil on sleep-promoting neurons from the ventrolateral preoptic nucleus: an in vitro pharmacologic study. Sleep, 27:19-25.

Gander PH, Marshall NS, Harris RB, et al. 2005. Sleep, sleepiness and motor vehicle accidents: a national survey. Aust N Z J Public Health, 29:16-21.

Gold LH, Balster RL. 1996. Evaluation of the cocaine like discriminative stimulus effects and reinforcing effects of modafinil. Psychopharmacol, 126:286-92.

Guy W. 1976. ECDEU assessment manual for psychopharmacology. Rockville, MD: National Institute of Mental Health.

Hermant JF, Rambert FA, Duteil J. 1991. Awakening properties of modafinil: effect on nocturnal activity in monkeys (Macaca mulatta) after acute and repeated administration. Psychopharmacology (Berl), 103:28-32. 
Hirshkowitz M, Black J. 2007. Effect of adjunctive modafinil on wakefulness and quality of life in patients with excessive sleepiness-associated obstructive sleep apnoea-hypopnoea syndrome: a 12-month, open-label extension. CNS Drugs, 21:407-16.

Ishizuka T, Sakamoto Y, Sakurai T. 2003. Modafinil increases histamine release in the anterior hypothalamus of rats. Neurosci Lett, 339; $143-6$.

Jasinski DR. 2000. An evaluation of the abuse potential of modafinil using methylphenidate as a reference. $J$ Psychopharmacol, 14:53-60.

Johns MW. 1991. A new method for measuring daytime sleepiness: the EpworthSleepiness Scale. Sleep, 14:540-5.

Kawachi I, Colditz GA, Stampfer MJ, et al. 1995. Prospective study of shift work and risk of coronary artery disease. Circulation, 92:3178-82.

Kingshott RN, Vennelle M, Coleman EL, et al. 2001. Randomized, doubleblind, placebo-controlled crossover trial of modafinil in the treatment of residual excessive sleepiness in sleep apnea/hypopnea syndrome. Am J Respir Crit Care Med, 163:918-23.

Krieger J, Kurtz D, Petiau C, et al. 1996. Long-term compliance with CPAP therapy in obstructive sleep apnea patients and in snorers. Sleep, 19 (9 Suppl):S136-S43.

Lagarde D, Batejat D, Van Beers P, et al. 1995. Interest of modafinil, a new psychostimulant, during a sixty-hour sleep deprivation experiment. Fundam Clin Pharmacol, 9:271-9.

Lin JS. 2000. Brain structures and mechanisms involved in the control of cortical activation and wakefulness, with emphasis on the posterior hypothalamus and histaminergic neurons. Sleep Med Rev, 4:471-503.

Lin JS, Gervasoni D, Hou Y, et al. 2000. Effects of amphetamine and modafinil on the sleep/wake cycle during experimental hypersomnia induced by sleep deprivation in the cat. J Sleep Res, 9:89-96.

Lin JS, Hou Y, Jouvet M. 1996. Potential brain neuronal targets for amphetamine-, methylphenidate-, and modafinil-induced wakefulness, c-fos immunocytochemistry in the cat. Proc Natl Acad Sci USA, 93:14128-33

Lin JS, Roussel B, Akaoka H, et al. 1992. Role of catecholamines in the modafinil and amphetamine induced wakefulness, a comparative pharmacological study in the cat. Brain Res, 591:319-326.

Lin JS, Sakai K, Jouvet M. 1988. Evidence for histaminergic arousal mechanisms in the hypothalamus of the cat. Neuropharmacology, 27:111-22.

Lin JS, Sakai K, Jouvet M. 1994. Hypothalamo-preoptic histaminergic projections in sleep-wake control in the cat. Eur J Neurosci, 6:618-25.

Lin JS, Sakai K, Vanni-Mercier G, et al. 1990. Involvement of histaminergic neurons in arousal mechanisms demonstrated with H3-receptor ligands in the cat. Brain Res, 523:325-30.

Lyznicki JM, Doege TC, Davis RM, et al. 1998. Sleepiness, Driving, and Motor Vehicle Crashes. JAMA, 279:1908-13.

Macey KE, Macey PM, Woo MA, et al. 2006. Inspiratory loading elicits aberrant fMRI signal changes in obstructive sleep apnea. Respir Physiol Neurobiol, 151:44-60.

MacLean AW, Davies DRT, Thiele K. 2003. The hazards and prevention of driving while sleepy. Sleep Med Reviews, 7:507-21.

Madras BK, Xie Z, Lin Z, et al. 2006. Modafinil occupies dopamine and norepinephrine transporters in vivo and modulates the transporters and trace amine activity in vitro. $J$ Pharmacol Exp Ther, 319:561-9.

Mignot E. 1998. Genetic and familial aspects of narcolepsy. Neurology, 50(Suppl 1):S16-S22.

Mignot E, Lin L, Finn L, et al. 2006. Correlates of sleep-onset REM periods during the Multiple Sleep Latency Test in community adults. Brain, 129:1609-23.

Mignot E, Nishino S, Guilleminault C, et al. 1994. Modafinil binds to the dopamine uptake carrier site with low affinity. Sleep, 17:436-7.

Mitler M, Carskadon M, Czeisler C, et al. 1988. Catastrophes, sleep, and public policy: consensus report. Sleep, 11:100-9.

Mitler MM, Gujavarty KS, Browman CP. 1982. Maintenance of wakefulness test: a polysomnographic technique for evaluating treatment efficacy in patients with excessive somnolence. Electroencephalogr Clin Neurophysiol, 53:658-61.
Mitler MM, Hajdukovic R. 1991. Relative efficacy of drugs for the treatment of sleepiness in narcolepsy. Sleep, 14:218-20.

Mitler MM, Harsh J, Hirshkowitz M, et al. 2000. Long-term efficacy and safety of modafinil (PROVIGIL) for the treatment of excessive daytime sleepiness associated with narcolepsy. Sleep Med, 1:231-43.

Moldofsky H, Broughton RJ, Hill JD. 2000. A randomized trial of the long-term, continued efficacy and safety of modafinil in narcolepsy. Sleep Med, 1:109-16.

Morrell MJ, Twigg G. 2006. Neural consequences of sleep disordered breathing: the role of intermittent hypoxia. Adv Exp Med Biol, 588:75-88.

Myrick H, Malcolm R, Taylor B, et al. 2004. Modafinil: preclinical, clinical, and post-marketing surveillance - a review of abuse liability issues. Ann Clin Psychiatry, 16:101-9.

National Sleep Foundation. 2002.Sleep in America Poll. Accessed 7 October 2007. URL:

http://www.sleepfoundation.org/site/c.huIXKjM0IxF/b.2417355/ k.143E/2002_Sleep_in_America_Poll.htm.

Nieto FJ, Young TB, Lind BK, et al. 2000. Association of sleep disordered breathing, sleep apnea and hypertension in a large community-based study. JAMA, 283:1829-36.

Nishino S, Mao J, Sampathkumaran R, et al. 1998. Increased dopaminergic transmission mediates the wake-promoting effects of CNS stimulants. Sleep Res Online, 1:49-61.

NUVIGIL $^{\circledR}$ [package insert]. 2007. Frazer, PA: Cephalon, Inc

Pack AI, Black JE, Schwartz JRL, et al. 2001. Modafinil as adjunct therapy for daytime sleepiness in obstructive sleep apnea. Am J Respir Crit Care Med, 164:1675-81.

Panckeri KA, Schotland HM, Pack AI, et al. 1996. Modafinil decreased hypersomnolence in the English bulldog, a natural animal model of sleep-disordered breathing. Sleep, 19:626-31.

Patel SR, White DP. Malhotra A, et al. 2003. Continuous positive airway pressure therapy for treating sleepiness in a diverse population with obstructive sleep apnea. Resultsof a meta-analysis. Arch Intern Med, 163:565-71.

Peppard PE, Young T, Palta M, et al. 2000. Prospective study of the association between sleep-disordered breathing and hypertension. N Engl J Med, 342:1378-94.

Pieters T, Collard P, Aubert G, et al. 1996. Acceptance and long-term compliance with nCPAP in patients with obstructive sleep apnoea syndrome. Eur Respir J, 9:939-44.

Pigeau R, NaitohP, Buguet A, et al. 1995. Modafinil, d-amphetamine and placebo during 64 hours of sustained mental work. I. Effects on mood, fatigue, cognitive performance and body temperature. J Sleep Res, 4:212-28.

Pollak CP. 2003. Con: modafinil has no role in management of sleep apnea. Am J Respir CritCare Med, 15:167:106-7.

Powell NB, Schectman KB, Riley RW, et al. 2007. Sleepy driver near-misses may predict accident risks. Sleep, 30:331-42.

Polotsky VY, Rubin AE, Balbir A, et al. 2006. Intermittent hypoxia causes REM sleep deficits and decreases EEG delta power in NREM sleep in the C57BL/6J mouse. Sleep Med, 7:7-16.

PROVIGIL $^{\circledR}$ [package insert]. 2007. Frazer, PA: Cephalon, Inc.

Reeves-Hoche MK, Meck R, Zwillich CW. 1994. Nasal CPAP: an objective evaluation of patient compliance. Am J Respir Crit Care Med, 149:149-54.

Robertson P Jr, DeCory HH, Madan A, et al. 2000. In vitro inhibition and induction of human hepatic cytochrome P450 enzymes by modafinil. Drug Metab Dispos, 28:664-71.

Robertson P Jr, Hellriegel ET, Arora S, et al. 2002a. Effect of modafinil at steady state on the single-dose pharmacokinetic profile of warfarin in healthy volunteers. J Clin Pharmacol, 42:205-14.

Robertson P Jr, Hellriegel ET, Arora S, et al. 2002b. Effect of modafinil on the pharmacokinetics of ethinyl estradiol and triazolam in healthy volunteers. Clin Pharmacol Ther, 71:46-56.

Robertson P Jr, Hellriegel ET. 2003. Clinical pharmacokinetic profile of modafinil. Clin Pharmacokinet, 42:123-37.

Roehrs T, Shore E, Papineau K, et al. 1996. A two-week sleep extension in sleepy normals. Sleep, 19:576-82. 
Roth T, Roehrs TA. 1996. Etiologies and sequelae of excessive daytime sleepiness. Clin Ther, 18:562-76.

Roth T, Schwartz JRL, Hirshkowitz M, et al. 2007. Evaluation of the safety of modafinil for the treatment of excessive sleepiness. J Clin Sleep Med, 15:3:595-602.

Rush CR, Kelly TH, Hays LR. 2002a. Discriminative-stimulus effects of modafinil in cocaine-trained humans. Drug AlcoholDepend, 67:311-22.

Rush CR, Kelly TH, Hays LR, et al. 2002b. Acute behavioral and physiological effects of modafinil in drug abusers. Behav Pharmacol, 13:105-15.

Sakurai T. 2007. The neural circuit of orexin (hypocretin): maintaining sleep and wakefulness. Nat Rev Neurosci, 8:171-181.

Scammell TE, Estabrooke IV, McCarthy MT, et al. 2000. Hypothalamic arousal regions are activated during modafinil-induced wakefulness. J Neurosci, 20:8620-8.

Schwartz JRL. 2005. Modafinil: new indications for wake promotion. Expert Opin Pharmacother, 6:115-29.

Schwartz JR, Feldman NT, Fry JM, et al. 2003a. Efficacy and safety of modafinil for improving daytime wakefulness in patients treated previously with psychostimulants. Sleep Med, 4:43-9.

Schwartz JR, Feldman NT, Bogan RK, et al. 2003b. Dosing regimen effects of modafinil for improving daytime wakefulness in patients with narcolepsy. Clin Neuropharmacol, 26:252-7.

Schwartz JR, Feldman NT, Bogan RK. 2005. Dose effects of modafinil in sustaining wakefulness in narcolepsy patients with residual evening sleepiness. J Neuropsychiatry Clin Neurosci, 17:405-12.

Schwartz JR, Hirshkowitz M, Erman MK, et al. 2003c. Modafinil as adjunct therapy for daytime sleepiness in obstructive sleep apnea: a 12-week, open-label study. Chest, 124:2192-9.

Schwartz JR, Nelson MT, Schwartz ER, et al. 2004. Effects of modafinil on wakefulness and executive function in patients with narcolepsy experiencing late-day sleepiness. Clin Neuropharmacol, 27:74-9.

Schwartz TL, Azhar N, Cole K, et al. 2004. An open-label study of adjunctive modafinil in patients with sedation related to serotonergic antidepressant therapy. J Clin Psychiatry, 65:1223-7.

Seidel W, Roth T, Roehrs T, et al. 1984. Treatment of a 12-hour shift of sleep schedule with benzodiazepines. Science, 224:1262-4.

Sforza E, Krieger J. 1992. Daytime sleepiness after long-term continuous positive airway pressure (CPAP) treatment in obstructive sleep apnea syndrome. J Neurol Sci, 110:21-6.

Shelton J, NishinoS, Vaught J, et al. 1995. Comparative effects of modafinil and amphetamine on daytime sleepiness and cataplexy of narcoleptic dogs. Sleep, 18:817-26.

Sherin JE, Elmquist JK, Torrealba F, et al. 1998. Innervation of histaminergic tuberomammillary neurons by GABAergic and galaninergic neurons in the ventrolateral preoptic nucleus of the rat. $J$ Neurosci, 18:4705-21.

Sherin JE, Shiromani PH, McCarley RW, et al. 1996. Activation of ventrolateral preoptic neurons during sleep. Science, 271:216-19.

Simon P, Hemet C, Ramassamy C, et al. 1995. Non-amphetamine mechanism of stimulant locomotor effect of modafinil in mice Eur Neuropsychopharmacol, 5:509-14.

Simon PH, Panissaud CH, Costentin J. 1994. The stimulant effect of modafinil on wakefulness is not associated with an increase in anxiety in mice: a comparison with dexamphetamine. Psychopharmacology, 114:597-600.
Singh M, Drake CL, Roth T. The Prevalence of multiple-sleep-onset REM periods in a population-based sample. Sleep, 7:890-5.

Tenkanen L, Sjoblom T, Kalimo R, et al. 1997. Shift work, occupation and coronary heart disease over 6 years of follow-up in the Helsinki Heart Study. Scand J Work Environ Health, 23:257-65.

Thorpy MJ, Schwartz JR, Kovacevic-Ristanovic R, et al. 2003. Initiating treatment with modafinil for control of excessive daytime sleepiness in patients switching from methylphenidate: an open-label safety study assessing three strategies. Psychopharmacology, 167:380-5.

US Modafinil in Narcolepsy Multicenter Study Group. 1998. Randomized trial of modafinil for the treatment of pathological somnolence in narcolepsy. Ann Neurol, 43:88-97.

US Modafinil in NarcolepsyMulticenter Study Group. 2000. Randomized trial of modafinil as a treatment for the excessive daytime somnolence of narcolepsy. Neurology, 54:1166-75.

Van Dongen HPA, Baynard MD, Maislin G, et al. 2004. Systemic interindividual differences in neurobehavioral impairment from sleep loss: evidence of trait-like differential vulnerability. Sleep, 27:423-33.

Veasey SC, Davis CW, Fenik P, et al. 2004. Long-term intermittent hypoxia in mice: protracted hypersomnolence with oxidative injury to sleepwake brain regions. Sleep, 27:194-201.

Walsh JK, Randazzo AC, Stone KL, et al. 2004. Modafinil improves alertness, vigilance, and executive function during simulated night shifts. Sleep, 27:434-9.

Ware JE Jr. 2007. SF-36 health survey update. Accessed 7 October 2007. URL: http://www.SF-36.org.

Warot D, CorrubleE, Payan C, et al. 1993. Subjective effects of modafinil, a new central adrenergic stimulant in healthy volunteers: a comparison with amphetamine, caffeine and placebo. Eur Psychiatry, 8:201-8.

Weaver TE, Laizner AM, Evans LK, et al. 1997. An instrument to measure functional status outcomes for disorders of excessive sleepiness. Sleep, 20:835-43.

Weaver TE, Maislin G, Dinges DF, et al. 2007. Relationship between hours of CPAP use and achieving normal levels of sleepiness and daily functioning. Sleep, 30:711-19.

Wise MS. 2006. Objective measures of sleepiness and wakefulness: application to the real world? J Clin Neurophysiology, 23:39-49.

Wisor JP, Nishino S, Sora I, et al. 2001. Dopaminergic role in stimulantinduced wakefulness. J Neurosci, 21:1787-94.

Wong YN, King SP, Simcoe D. 1999b. Open-label, single-dose pharmacokinetic study of modafinil tablets: influence of age and gender in normal subjects. J Clin Pharmacol, 39:281-8.

Wong YN, Simcoe D, Hartman LN, et al. 1999a. A double-blind, placebocontrolled, ascending-dose evaluation of the pharmacokinetics and tolerability of modafinil tablets in healthy male volunteers. $J$ Clin Pharmacol, 39:30-40.

Young T, Palta M, Dempsey J, et al. 1993. The occurrence of sleep-disordered breathing among middle-aged adults. $N$ Engl J Med, 328:1230-5.

Zhu Y, Fenik P, Zhan G, et al. 2007. Selective loss of catecholaminergic wake-active neurons in a murine sleep apnea model. J Neuroscience, $27: 10060-71$ 
